\title{
Immunoglobulin superfamily member 10 is a novel prognostic biomarker for breast cancer
}

\author{
Mengxue Wang ${ }^{1}$, Meng Dai ${ }^{2}$, YuShen Wu ${ }^{1}$, Ziying $\mathbf{Y i}^{1}{ }^{1}$, Yunhai Li ${ }^{\text {Corresp., } 3}{ }^{3}$, Guosheng Ren ${ }^{\text {Corresp. } 1}$ \\ ${ }^{1}$ Chongqing Key Laboratory of Molecular Oncology and Epigenetics, The First Affiliated Hospital of Chongqing Medical University, Chongqing, China \\ 2 Department of Oncology, The First People's Hospital of Neijiang, Neijiang, Sichuan, China \\ 3 Department of Endocrine and Breast Surgery, The First Affiliated Hospital of Chongqing Medical University, Chongqing, China \\ Corresponding Authors: Yunhai Li, Guosheng Ren \\ Email address: leeyh90@hospital.cqmu.edu.cn, rengs726@126.com
}

Background. Immunoglobulin superfamily member 10 (IGSF10) is a member of the immunoglobulin superfamily that is expressed at high levels in both the gallbladder and ovary. Currently, the role and possible mechanism of IGSF10 in breast cancer remain unclear. Method. By applying real-time quantitative polymerase chain reaction (qRT-PCR) and immunohistochemistry (IHC), the expression of IGSF10 in breast cancer cells and tissues was detected. We collected the clinical information from 700 patients with breast cancer in The Cancer Genome Atlas (TCGA), and analyzed the relationship between IGSF10 expression and the clinicopathological features and survival outcomes of these patients. The potential mechanisms and pathways associated with IGSF10 in breast cancer were explored by performing a gene set enrichment analysis (GSEA). Results. According to TCGA data, qRT-PCR and IHC experiments, levels of the IGSF10 mRNA and protein were significantly decreased in breast cancer tissues. IGSF10 expression was significantly correlated with age, tumor size, and tumor stage. Moreover, shorter overall survival (OS) and relapse-free survival (RFS) correlated with lower IGSF10 expression, according to the survival analysis. The multivariate analysis identified that IGSF10 as an independent prognostic factor for the OS (hazard ratio $(H R)=1.793,95 \%$ confidence interval $(\mathrm{Cl})$ : $1.141-2.815, P=0.011)$ and RFS ( $\mathrm{HR}=2.298,95 \% \mathrm{Cl}: 1.317-4.010, P=0.003)$ of patients with breast cancer. Based on the GSEA, IGSF10 was involved in DNA repair, cell cycle, and glycolysis. IGSF10 was also associated with the PI3K/Akt/mTOR and mTORC1 signaling pathways. Conclusions. This study revealed a clear relationship between IGSF10 expression and the tumorigenesis of breast cancer for the first time. Therefore, further studies are needed to understand the mechanism of IGSF10 in breast cancer. 


\section{Immunoglobulin superfamily member 10 is a novel prognostic}

\section{2 biomarker for breast cancer}

3

4 Mengxue Wang ${ }^{1}$, Meng Dai ${ }^{2}$, Yushen Wu ${ }^{1}$, Ziying Yi ${ }^{1}$, Yunhai Li ${ }^{3,{ }^{*}}$, Guosheng $\operatorname{Ren}^{1,3,{ }^{*}}$

5

$6{ }^{1}$ Chongqing Key Laboratory of Molecular Oncology and Epigenetics, The First Affiliated Hospital 7 of Chongqing Medical University, Chongqing, China

$8 \quad 2$ Department of Oncology, The First People's Hospital of Neijiang, Neijiang, China

$9 \quad{ }^{3}$ Department of Endocrine and Breast Surgery, The First Affiliated Hospital of Chongqing Medical 10 University, Chongqing, China

*Corresponding authors:

13 Yunhai Li, E-mail: leeyh90@hospital.cqmu.edu.cn

Department of Endocrine and Breast Surgery, The First Affiliated Hospital of Chongqing Medical University, No. 1 Youyi Road, Yuzhong District, Chongqing, 400016, China. Phone: 00862389011477; Fax: 0086-2389012305 China. Phone: 0086-2389011477; Fax: 0086-2389012305 


\section{Abstract}

Background. Immunoglobulin superfamily member 10 (IGSF10) is a member of the immunoglobulin superfamily that is expressed at high levels in both the gallbladder and ovary. Currently, the role and possible mechanism of IGSF10 in breast cancer remain unclear.

Method. By applying real-time quantitative polymerase chain reaction (qRT-PCR) and immunohistochemistry (IHC), the expression of IGSF10 in breast cancer cells and tissues was detected. We collected the clinical information from 700 patients with breast cancer in The Cancer Genome Atlas (TCGA), and analyzed the relationship between IGSF10 expression and the clinicopathological features and survival outcomes of these patients. The potential mechanisms and pathways associated with IGSF10 in breast cancer were explored by performing a gene set enrichment analysis (GSEA).

Results. According to TCGA data, qRT-PCR and IHC experiments, levels of the IGSF10 mRNA and protein were significantly decreased in breast cancer tissues. IGSF10 expression was significantly correlated with age, tumor size, and tumor stage. Moreover, shorter overall survival (OS) and relapse-free survival (RFS) correlated with lower IGSF10 expression, according to the survival analysis. The multivariate analysis identified that IGSF10 as an independent prognostic factor for the OS (hazard ratio (HR) $=1.793,95 \%$ confidence interval (CI): $1.141-2.815, P=0.011$ ) and RFS (HR=2.298, 95\% CI: $1.317-4.010, P=0.003)$ of patients with breast cancer. Based on the GSEA, IGSF10 was involved in DNA repair, cell cycle, and glycolysis. IGSF10 was also associated with the PI3K/Akt/mTOR and mTORC1 signaling pathways.

Conclusions. This study revealed a clear relationship between IGSF10 expression and the tumorigenesis of breast cancer for the first time. Therefore, further studies are needed to understand the mechanism of IGSF10 in breast cancer. 
Breast cancer is a common malignancy that seriously threatens women's health. Approximately 2.1 million female patients were newly diagnosed with breast cancer worldwide in 2018. Breast cancer accounts for one-quarter of all female cancer cases (Bray et al., 2018). As a heterogeneous disease, the initiation and development of breast cancer are affected by both genetic and environmental factors (Yang et al., 2019). Despite continuous advances in surgical techniques, biological drugs and targeted therapies, breast cancer remains an arduous clinical problem (Woolston, 2015). Therefore, the identification of breast cancer biomarkers is crucial for obtaining an understanding of the tumorigenesis and accurate cancer prognosis, as biomarkers may assist with the clinical diagnosis and serve as potential tumor therapeutic targets in patients with breast cancer (Costa-Pinheiro et al., 2015; John R Prensner, 2012; Qiao et al., 2019).

Immunoglobulin superfamily member 10 (IGSF10) is a gene involved in cell differentiation and developmental processes (Thutkawkorapin et al., 2016). Mutations in IGSF10 delay human puberty (Howard, 2018; Howard et al., 2016). Moreover, during embryonic development, mutations in IGSF10 lead to the dysregulation of gonadotropin-releasing hormone (GnRH)associated neuronal migration. Based on accumulating evidence, IGSF10 deficiency may lead to a transient GnRH deficiency and reversible congenital hypogonadotropic hypogonadism (Amato et al., 2019; Howard, 2018). Moreover, mutations in IGSF10 likely contribute to an increased risk of rectal and gastric cancers (Thutkawkorapin et al., 2016). As shown in the study by Daino et al., IGSF10 is significantly downregulated in a rat model of alpha-radiation-induced osteosarcoma (Daino et al., 2009). The expression of IGSF10 is downregulated in lung cancer tissues, and decreased expression of IGSF10 correlated with a poor prognosis for patients with lung cancer (Ling et al., 2020). However, the biological roles of IGSF10 in the majority of cancers have not been investigated, and its role in breast cancer remains largely unknown.

In the present study, the expression of IGSF10 in collected breast cancer tissues was examined using qRT-PCR and IHC. The clinicopathological features of the disease based on IGSF10 expression and Kaplan-Meier survival curves were analyzed using public data from The Cancer Genome Atlas (TCGA) database. In addition, a gene set enrichment analysis (GSEA) was 
79

80

81

82

83

84

85

86

87

88

89

90

91

102

103

104

105

106

performed to explore the potential mechanisms and signaling pathways by which IGSF 10 may mediate breast tumorigenesis.

\section{Materials \& Methods}

\section{Cell culture}

The breast cancer cell lines: MDA-MB-231, MCF-7, BT-549, ZR-75-30, SKBR-3, and T47D (ATCC, Manassas, VA, USA) were maintained as previously described (Zhang et al., 2019). The normal mammary epithelial cell line MCF-10A was also maintained as previously described (Debnath, 2003). All cell lines were cultured in a humidified incubator at $37^{\circ} \mathrm{C}$ with an atmosphere containing $5 \% \mathrm{CO}_{2}$.

\section{Patients with breast cancer and tissue samples}

TCGA data were utilized as previously described (Qiu, 2018). In the present study, we analyzed IGSF10 expression in 1095 patients with breast cancer in TCGA database. We included 700 patients with breast cancer who had complete RNA-seq data and complete clinical information to analyze the clinical correlation between IGSF10 expression and breast cancer. The following clinical information was collected: age, tumor size, lymph node status, tumor, node, metastasis (TNM) stage, estrogen receptor (ER) status, progesterone receptor (PR) status, human epidermal growth factor receptor 2 (HER2) status, and follow-up information.

Breast cancer tissue samples were collected as previously described (Li et al., 2018). Specifically, we collected 52 pairs of breast tumor and adjacent normal tissues from patients with breast cancer during surgery between 2014 and 2016 at The First Affiliated Hospital of Chongqing Medical University. The collected tissues were used for real-time quantitative polymerase chain reaction (RT-qPCR) and immunohistochemistry (IHC) analyses. All specimens were stored in liquid nitrogen. The collection and use of the tissues were approved by the Institutional Ethics Committees of the First Affiliated Hospital of Chongqing Medical University. The approval number allocated to this study by the Institutional Ethics Committees is 2017 Research Ethics (2017-012). 
107

108

109

110

111

112

113

114

115

116

117

118

119

120

121

122

123

124

125

126

127

128

129

130

131

132

133

134

135

\section{RNA isolation and RT-qPCR}

As described in a previous study (Qiu et al., 2018), we followed the manufacturer's instructions and extracted the total RNA using TRIzol reagent (Life Technologies Inc., USA). RT-qPCR of 21 paired tissues was performed with an ABI 7500 Real-Time PCR System (Applied Biosystems) to examine IGSF10 expression. Relative quantification of the expression of the IGSF10 mRNA was standardized to the expression levels of GAPDH. The following primer pairs were used in the present study:

Forward primer (IGSF 10): 5'-TTGGAGTTTGCCTGATGGAAC-3';

Reverse primer (IGSF10): 5'-CGCTACCCCAACTTTGTTGAAG-3';

Forward primer (GAPDH): 5'-GGAGCGAGATCCCTCCAAAAT-3';

Reverse primer (GAPDH): 5'-GGCTGTTGTCATACTTCTCATGG-3'.

\section{IHC}

The procedure used for IHC was described in a previous study (Li et al., 2018). An anti-IGSF10 rabbit polyclonal antibody (ab197671, 1:100, Abcam), a secondary antibody (ZSGB 1:100 SPN9001) and HRP (ZSGB 1:100 SPN9001) were used. Thirty-one paired tissues were subjected to IHC. The IHC staining intensity scoring criteria were as follows: 0 , none; 1, weak; 2, medium; and 3, strong. The scoring criteria for the proportion of positive tumor cells were as follows: $0,<$ $5 \% ; 1,5 \%-25 \% ; 2,26 \%-50 \% ; 3,51 \%-75 \%$; and 4, > 75\%. An overall score was derived by multiplying the intensity and percentage scores.

\section{Bioinformatics analyses}

The expression of IGSF10 in different subtypes of breast cancer was analyzed using UALCAN, a web portal for evaluating gene expression in different tumor subtypes stratified according to the various clinicopathological features of patients in TCGA database (Chandrashekar et al., 2017).

The expression of the IGSF10 mRNA in different breast cancer datasets was evaluated using Oncomine gene expression array datasets (Rhodes et al., 2004). The cutoff $P$-value and absolute 
136

137

138

139

140

141

142

143

144

145

146

147

148

149

150

151

152

153

154

155

156

157

158

159

160

161

162

163

3

fold change were defined as 0.01 and 2, respectively.

The relationship between IGSF10 expression and the prognosis of patients with breast cancer presenting different molecular subtypes was analyzed using a Kaplan-Meier plotter (http://kmplot.com/analysis/) (András Lánczky et al., 2016). The Affymetrix probe set ID of IGSF10 is 230670_at. Patients were automatically stratified into IGSF10-high and IGSF10-low groups according to the mean expression of the IGSF10 mRNA.

\section{GSEA}

This method was described in previous study (Jiao et al., 2018). We performed a GSEA (http://software.broadinstitute.org/gsea) to explore the association between IGSF10 expression and biological processes/pathways according to the instructions of the user guide. We performed the GSEA using a microarray dataset (GSE1456) and TCGA microarray dataset.

\section{Additional statistical analyses}

All statistical analyses were performed using SPSS software (version 23.0). OS and RFS were calculated by constructing Kaplan-Meier curves. The differences between two groups were evaluated using Student's $\mathrm{t}$ test. Significance was set to a $P$-value less than 0.05 .

\section{Results}

\section{The expression of IGSF10 in breast cancer and its clinicopathological features}

We examined the expression of the IGSF10 mRNA in 1095 patients with breast cancer in TCGA database. Based on our results, the IGSF10 mRNA was expressed at higher levels in adjacent normal tissues than in breast cancer tissues (Figure 1A). We then detected the differences in IGSF 10 expression in 21 paired tissue samples using RT-qPCR. Consistent with the results from TCGA database, IGSF10 expression was substantially downregulated in breast cancer tissues (Figure 1B and Supplemental Table 1). We collected 31 pairs of breast cancer and corresponding normal tissues and performed IHC. The staining scores of the breast cancer tissues were significantly lower than the adjacent normal tissues (Figure 1C-1G). Finally, we examined the 
164

165

166

167

168

169

170

171

172

173

174

175

176

177

178

179

180

181

182

183

184

185

186

187

188

189

190

191

192

expression of the IGSF10 mRNA in breast cell lines. IGSF10 was expressed at higher levels in the normal breast epithelial cell line MCF10A than in the breast cancer cell lines (Figure 1E and Supplemental Table 2).

Seven hundred patients with breast cancer in the TCGA cohort were analyzed to further confirm the correlation between IGSF10 expression and breast cancer (Supplemental Table 3). IGSF10 expression correlated with age $(P<0.001)$, tumor size $(P=0.003)$, and TNM stage $(P=0.03)$ (Table 1).

\section{High IGSF10 expression correlated with a better prognosis for patients with breast cancer}

The associations of IGSF10 expression with overall survival (OS) and relapse-free survival (RFS) were evaluated using Kaplan-Meier survival curves. Patients in TCGA dataset were stratified by the median IGSF10 mRNA expression level (Supplemental Table 4). Patients with high IGSF10 expression were significantly more likely to experience prolonged OS (hazard ratio $(\mathrm{HR})=0.63,95 \%$ confidence interval $(\mathrm{CI}): 0.41-0.97, P<0.05)($ Figure $2 \mathrm{~A})$ and RFS $(\mathrm{HR}=0.53$, 95\% CI: 0.30-0.93, $P<0.05$ ) (Figure 2B) than patients with low IGSF10 expression. Subsequently, we used the UALCAN database to further evaluate the prognostic value of IGSF10 by stratifying patients into different molecular subtypes. Decreased levels of the IGSF10 mRNA were observed in luminal, HER2-positive, and triple-negative breast cancer samples compared with normal samples (Figure 3A). Low IGSF10 expression was significantly correlated with a shorter OS of patients with basal $(\mathrm{HR}=0.44,95 \% \mathrm{CI}: 0.22-0.86, P=0.013)$, luminal A (HR=0.47, 95\% CI: $0.25-$ $0.88, P=0.017)$, and HER2 $+(\mathrm{HR}=0.28,95 \% \mathrm{CI}: 0.09-0.81, P=0.012)$ breast cancer subtypes (Figures 3B-3E). However, a significant relationship was not observed between the expression of IGSF10 and OS of patients with the luminal B subtype $(\mathrm{HR}=0.61,95 \% \mathrm{CI}: 0.3-1.23, P=0.17)$ (Figure 3D). The multivariate Cox regression analysis of TCGA patients with breast cancer showed that IGSF10 was an independent prognostic factor for OS (HR=1.793, 95\% CI: 1.1412.815, $P=0.011)$ and RFS $(\mathrm{HR}=2.298,95 \% \mathrm{CI}: 1.317-4.010, P=0.003)$ (Table 2).

\section{Potential biological roles and signaling pathways related to IGSF10}


Potential mechanisms and signaling pathways that may be related to the ability of IGSF10 to regulate the development of breast cancer were explored by conducting a GSEA. According to the median value of IGSF10 expression in the microarray dataset (GSE1456) and TCGA dataset, we assigned patients to two groups. Nine gene sets were enriched in the GSE1456 dataset and 16 gene sets were enriched in TCGA dataset $(P<0.05$; false discovery rate $(\mathrm{FDR})<0.25)$ (Figure 4A-4B and Supplemental Table 5). Interestingly, IGSF10 expression was positively correlated with several cancer-related biological processes, including DNA repair (HALLMARK_DNA_REPAIR), cell cycle (HALLMARK_G2M_CKECKPOINT), and glycolysis (HALLMARK_GLYCOLYSIS) pathways in both datasets (Figure 4C-4E). The PI3K/Akt/mTOR and mTORC1 signaling pathways were also associated with IGSF10 (Figure 4F-4G). Moreover, in TCGA dataset, the transforming $\quad$ growth factor- $\beta \quad$ (TGF- $\beta$ ) signaling $\quad$ pathway (HALLMARK_TGF_BETA_SIGNALING), epithelial mesenchymal transition (EMT) (HALLMARK_EPITHELIAL_MESENCHYMAL_TRANSITION) and tumor necrosis factor (TNF) signaling pathway (HALLMARK_TNFA_SIGNALING_VIA_NFKB) were significantly enriched in the IGSF 10-low group (Supplemental Figure 1A). These results indicated a possible mechanism underlying the role of IGSF10 in the tumorigenesis of breast cancer.

\section{Discussion}

In recent years, numerous molecular prognostic biomarkers have been identified and validated in cancers, including breast cancer (Nicolini, 2018). In the present study, we identified IGSF10 as a potential prognostic biomarker for breast cancer and described a possible mechanism underlying its role in the tumorigenesis of breast cancer.

In the present study, we explored the role of IGSF10 in breast cancer by analyzing TCGA data and performing RT-qPCR and IHC. Our data indicated that IGSF10 expression was significantly downregulated in breast cancer tissues. Consistent with our results, multiple datasets in the Oncomine database suggested that IGSF10 expression was down-regulated in breast cancer tissues (absolute fold change $>$ 2) including TCGA Breast, Karnoub Breast (Karnoub et al., 2007), Zhao 
220

221

222

223

224

225

226

227

228

229

230

231

232

233

234

235

236

237

238

239

240

241

242

243

244

245

246

Breast (Zhao et al., 2004), Richardson Breast 2 (Richardson et al., 2006), and Finak Breast (Finak et al., 2008) datasets (Supplemental Table 6). Based on the analysis of the data in the UALCAN database, we found that IGSF10 expression correlated with the molecular subtype of breast cancer. In addition, IGSF10 expression was closely associated with age, tumor size, and TNM stage. Accordingly, IGSF10 may play a crucial role in breast cancer and have the potential to be targeted by anticancer therapy. Moreover, the survival analysis indicated that patients with breast cancer presenting higher IGSF10 expression experienced prolonged OS and RFS. The multivariate analysis identified IGSF10 as an independent prognostic factor for patients with breast cancer. Interestingly, in the subgroup analysis, IGSF10 expression was significantly correlated with OS in patients with basal, luminal A and HER2-positive breast cancer. Thus, IGSF10 may be a prognostic biomarker for breast cancer.

IGSF10 may exert an important effect on tumorigenesis. Ling and colleagues claimed that IGSF10 knockout promotes the development of lung cancer and that IGSF10 mainly activates the integrin- $\beta 1 /$ FAK pathway in lung cancer (Ling et al., 2020). In one family with gastric and colorectal cancers, Thutkawkorapin et al. identified 12 new nonsynonymous single nucleotide variants in 12 different genes, including IGSF10, with potential contributions to an increased cancer risk (Thutkawkorapin et al., 2016). Chang et al. identified new mutations in patients with endometrial cancer in Taiwan by performing whole-exome sequencing and identified a potential association between IGSF10, a passenger gene, with endometrial cancer (Chang, 2017). However, to our knowledge, no studies have reported the possible functions and mechanisms of IGSF10 in breast cancer.

During the past decade, accumulating evidence has revealed clear correlations between immunoglobulin superfamily members and human diseases. For instance, loss-of-function mutations in IGSF1 result in an X-linked syndrome of central hypothyroidism and testicular enlargement. IGSF1 mutations in male patients lead to a late increase in testosterone levels (Howard et al., 2016; Roche et al., 2018; Sun et al., 2012). Significantly prolonged OS was observed in pediatric patients with mixed-lineage leukemia-rearranged acute monoblastic 
247 leukemia with $\mathrm{t}(9 ; 11)(\mathrm{p} 22 ; \mathrm{q} 23)$ and high IGSF4 expression than in patients with low IGSF4 248 expression (Kuipers et al., 2011). As shown in the study by Wang et al., IGSF8 promotes 249 melanoma proliferation and metastasis by negatively regulating the TGF- $\beta$ signaling pathway 250 (Wang et al., 2015).

251

In the present study, potential biological roles and signaling pathways that may be related to IGSF10 expression in breast cancer were analyzed by conducting a GSEA. Several biological

253

254

255

256

257

258

259

260

261

262

263

264

265

266

267

268

269

270

271

272

273

processes, including DNA repair, the cell cycle, and glycolysis, were associated with IGSF10. Among these processes, the genomic integrity is maintained through DNA repair pathways. The dysregulation of DNA repair leads to changes in the genome and causes physiological changes in cells that drive tumor initiation (Jeggo, 2016; Khanna, 2015; Mouw, 2017). The cell cycle regulates tumor growth and glycolysis modulates the heterogeneity of the tumor microenvironment. These biological processes are related to tumor progression, metastasis and drug resistance (Jahagirdar et al., 2018). Moreover, in human malignancies, the mTORC1 and PI3K/Akt/mTOR signaling pathways are usually abnormally activated and promote the development of malignancies (Hare, 2017). According to previous studies, mTORC1 promotes cell growth by activating key anabolic processes and the dysregulation of mTORC1 is the basis of many human cancers (Ben-Sahra, 2017; Keppler-Noreuil, 2016). The PI3K/Akt/mTOR pathway is related to various biological processes in breast cancer, such as tumorigenesis, cellular transformation, tumor progression, and drug resistance (Guerrero-Zotano et al., 2016). Therefore, we speculated that IGSF10 might mechanistically regulate the growth of breast cancer cells through the mTORC1 and PI3K/Akt/mTOR signaling pathways. Intriguingly, IGSF10 was associated with EMT, the TGF- $\beta$ signaling pathway and the TNF signaling pathway in TCGA database. The TGF- $\beta$ signaling pathway was reported to be associated with various tumors and it regulates the biological processes in multiple cancers, including growth, migration, invasion, apoptosis and the EMT (Bedi et al., 2012; Tang et al., 2017; Yu et al., 2018; Zhao et al., 2018). The EMT plays crucial roles in the metastasis and invasion of breast cancer by regulating cell motility and invasiveness (Feng et al., 2016). Moreover, TNF- $\alpha$ is strongly correlated with 
274 inflammation in breast tumors, and an increase in its expression is strongly correlated with relapse 275 and advanced disease (Katanov et al., 2015). However, further studies are needed to elucidate the 276 role of IGSF10 in breast cancer and the detailed mechanisms by which IGSF10 modulates these 277 related signaling pathways.

Conclusions

280

281

282

283

284

285

286

287

288

289

290

291

292

293

294

295

296

297

298

299

In summary, IGSF10 was expressed at a low level in breast cancer. IGSF10 expression was significantly correlated with age, tumor size, and tumor stage. More importantly, IGSF10 was an independent prognostic factor for better outcomes in patients with breast cancer. In addition, the GSEA results identified significant associations between IGSF10 expression and DNA repair, cell cycle, glycolysis, and the mTORC1 and PI3K/Akt/mTOR signaling pathways. Overall, we suggested a novel role for IGSF10 in breast cancer. Our data may provide new insights into the identification of potential therapeutic targets in patients with breast cancer.

\section{Acknowledgments}

I greatly appreciate the assistance and encouragement from my tutor.

\section{References}

András, Lánczky, Á, Nagy, G, Bottai, G, Munkácsy, A, Szabó, L, Santarpia, Győrffy B. (2016). miRpower: a web-tool to validate survival-associated miRNAs utilizing expression data from 2178 breast cancer patients. Breast Cancer Res Treat.160(3), 439-446. doi:10.1007/s10549-016-4013-7

Amato, L. G. L., Montenegro, L. R., Lerario, A. M., Jorge, A. A. L., Guerra Junior, G., Schnoll, C., Renck, A. C., Trarbach, E. B., Costa, E. M. F., Mendonca, B. B., Latronico, A. C., \& Silveira, L. F. G. (2019). New genetic findings in a large cohort of congenital hypogonadotropic hypogonadism. Eur. J. Endocrinol., 181(2), 103-119. doi:10.1530/eje- 
300

301

302

303

304

305

306

307

308

309

310

311

312

313

314

315

316

317

318

319

320

321

322

323

324

325

326

18-0764

Bedi, Atul, Chang, Xiaofei, Noonan, Kimberly, Pham, Vui, Bedi, Rishi, Fertig, Elana J., Considine, Michael, Califano, Joseph A., Borrello, Ivan, Chung, Christine H., Sidransky, David, \& Ravi, Rajani. (2012). Inhibition of TGF- $\beta$ enhances the in vivo antitumor efficacy of EGF receptor-targeted therapy. Molecular cancer therapeutics, 11(11), 2429-2439. doi:10.1158/1535-7163.MCT-12-0101-T

Ben-Sahra, I., \& Manning, B. D. (2017). mTORC1 signaling and the metabolic control of cell growth. Curr. Opin. Cell Biol., 45, 72-82. doi:10.1016/j.ceb.2017.02.012

Bray, F., Ferlay, J., Soerjomataram, I., Siegel, R. L., Torre, L. A., \& Jemal, A. (2018). Global cancer statistics 2018: GLOBOCAN estimates of incidence and mortality worldwide for 36 cancers in 185 countries. CA Cancer J Clin, 68(6), 394-424. doi:10.3322/caac.21492

Chandrashekar, D. S., Bashel, B., Balasubramanya, S. A. H., Creighton, C. J., Ponce-Rodriguez, I., Chakravarthi, Bvsk, \& Varambally, S. (2017). UALCAN: A Portal for Facilitating Tumor Subgroup Gene Expression and Survival Analyses. Neoplasia, 19(8), 649-658. doi:10.1016/j.neo.2017.05.002

Chang, Y. S., Huang, H. D., Yeh, K. T., \& Chang, J. G. (2017). Identification of novel mutations in endometrial cancer patients by whole-exome sequencing. Int. J. Oncol., 50(5), 17781784. doi:10.3892/ijo.2017.3919

Costa-Pinheiro, P., Montezuma, D., Henrique, R., \& Jerónimo, C. (2015). Diagnostic and prognostic epigenetic biomarkers in cancer. Epigenomics, 7(6), 1003-1015. doi:10.2217/epi.15.56

Daino, K., Ugolin, N., Altmeyer-Morel, S., Guilly, M. N., \& Chevillard, S. (2009). Gene expression profiling of alpha-radiation-induced rat osteosarcomas: identification of dysregulated genes involved in radiation-induced tumorigenesis of bone. Int. J. Cancer, 125(3), 612-620. doi:10.1002/ijc.24392

Debnath, J., Muthuswamy, S. K., \& Brugge, J. S. (2003). Morphogenesis and oncogenesis of MCF-10A mammary epithelial acini grown in three-dimensional basement membrane 
327

328

329

330

331

332

333

334

335

336

337

338

339

340

341

342

343

344

345

346

347

348

349

350

351

352

353

cultures. Methods, 30(3), 256-268. doi:10.1016/s1046-2023(03)00032-x

Feng, Meibao, Feng, Jieqiong, Chen, Wuzhen, Wang, Wubin, Wu, Xuesong, Zhang, Jing, Xu, Fangying, \& Lai, Maode. (2016). Lipocalin2 suppresses metastasis of colorectal cancer by attenuating NF-kB-dependent activation of snail and epithelial mesenchymal transition. Molecular cancer, 15(1), 77.

Finak, G., Bertos, N., Pepin, F., Sadekova, S., Souleimanova, M., Zhao, H., Chen, H., Omeroglu, G., Meterissian, S., Omeroglu, A., Hallett, M., \& Park, M. (2008). Stromal gene expression predicts clinical outcome in breast cancer. Nat. Med., 14(5), 518-527. doi:10.1038/nm1764

Guerrero-Zotano, A., Mayer, I. A., \& Arteaga, C. L. (2016). PI3K/AKT/mTOR: role in breast cancer progression, drug resistance, and treatment. Cancer Metastasis Rev., 35(4), 515524. doi:10.1007/s10555-016-9637-x

Hare, S. H., \& Harvey, A. J. (2017). mTOR function and therapeutic targeting in breast cancer. Am J Cancer Res, 7(3), 383-404.

Howard, S. R. (2018). Genes underlying delayed puberty. Mol. Cell. Endocrinol., 476, 119-128. doi:10.1016/j.mce.2018.05.001

Howard, S. R., Guasti, L., Ruiz-Babot, G., Mancini, A., David, A., Storr, H. L., Metherell, L. A., Sternberg, M. J., Cabrera, C. P., Warren, H. R., Barnes, M. R., Quinton, R., de Roux, N., Young, J., Guiochon-Mantel, A., Wehkalampi, K., André, V., Gothilf, Y., Cariboni, A., \& Dunkel, L. (2016). IGSF10 mutations dysregulate gonadotropin-releasing hormone neuronal migration resulting in delayed puberty. EMBO Mol Med, 8(6), 626-642. doi:10.15252/emmm.201606250

Jahagirdar, D., Gore, C. R., Patel, H., Maria, K., Tandon, I., \& Sharma, N. K. (2018). Induction of Apoptotic Death and Cell Cycle Arrest in HeLa Cells by Extracellular Factors of Breast Cancer Cells. Asian Pac. J. Cancer Prev., 19(12), 3307-3316. doi:10.31557/apjcp.2018.19.12.3307

Jeggo, P. A., Pearl, L. H., \& Carr, A. M. (2016). DNA repair, genome stability and cancer: a historical perspective. Nat. Rev. Cancer, 16(1), 35-42. doi:10.1038/nrc.2015.4 
354

355

356

357

358

359

360

361

362

363

364

365

366

367

368

369

370

371

372

373

374

375

376

377

378

379

380

Jiao, Y., Fu, Z., Li, Y., Meng, L., \& Liu, Y. (2018). High EIF2B5 mRNA expression and its prognostic significance in liver cancer: a study based on the TCGA and GEO database. Cancer Manag Res, 10, 6003-6014. doi:10.2147/cmar.S185459

JR, Prensner, MA, Rubin, JT, Wei, \& medicine, Chinnaiyan AM. (2012). Beyond PSA: the next generation of prostate cancer biomarkers. Science Translational Medicine, 4(127),doi:10.1126/scitranslmed.3003180.

Karnoub, A. E., Dash, A. B., Vo, A. P., Sullivan, A., Brooks, M. W., Bell, G. W., Richardson, A. L., Polyak, K., Tubo, R., \& Weinberg, R. A. (2007). Mesenchymal stem cells within tumour stroma promote breast cancer metastasis. Nature, 449(7162), 557-563. doi:10.1038/nature 06188

Katanov, Christina, Lerrer, Shalom, Liubomirski, Yulia, Leider-Trejo, Leonor, Meshel, Tsipi, Bar, Jair, Feniger-Barish, Rotem, Kamer, Iris, Soria-Artzi, Gali, Kahani, Hadar, Banerjee, Debabrata, \& Ben-Baruch, Adit. (2015). Regulation of the inflammatory profile of stromal cells in human breast cancer: prominent roles for TNF- $\alpha$ and the NF-kB pathway. Stem cell research \& therapy, 6, 87. doi:10.1186/s13287-015-0080-7Keppler-Noreuil, K. M., Parker, V. E., Darling, T. N., \& Martinez-Agosto, J. A. (2016). Somatic overgrowth disorders of the PI3K/AKT/mTOR pathway \& therapeutic strategies. Am J Med Genet C Semin Med Genet, 172(4), 402-421. doi:10.1002/ajmg.c.31531

Khanna, A. (2015). DNA damage in cancer therapeutics: a boon or a curse? Cancer Res., 75(11), 2133-2138. doi:10.1158/0008-5472.Can-14-3247

Kuipers, J. E., Coenen, E. A., Balgobind, B. V., Stary, J., Baruchel, A., de Haas, V., de Bont, E. S., Reinhardt, D., Kaspers, G. J., Cloos, J., Danen-van Oorschot, A. A., den Boer, M. L., Marschalek, R., Meyer, C., Pieters, R., Zwaan, C. M., \& van den Heuvel-Eibrink, M. M. (2011). High IGSF4 expression in pediatric M5 acute myeloid leukemia with t(9;11)(p22;q23). Blood, 117(3), 928-935. doi:10.1182/blood-2010-05-286138

Li, Yunhai, Huang, Jing, Zeng, Beilei, Yang, Dejuan, Sun, Jiazheng, Yin, Xuedong, Lu, Mengqi, Qiu, Zhu, Peng, Weiyan, Xiang, Tingxiu, Li, Hongzhong, \& Ren, Guosheng. (2018). 
381

382

383

384

385

386

387

388

389

390

391

392

393

394

395

396

397

398

399

400

401

402

403

404

405

406

407

PSMD2 regulates breast cancer cell proliferation and cell cycle progression by modulating p21 and p27 proteasomal degradation. Cancer letters, 430, 109-122. doi:10.1016/j.canlet.2018.05.018

Ling, Bo, Liao, Xianjiu, Huang, Yuanhe, Liang, Lingling, Jiang, Yan, Pang, Yaqin, \& Qi, Guangzi. (2020). Identification of prognostic markers of lung cancer through bioinformatics analysis and in vitro experiments. Int. J. Oncol., 56(1), 193-205. doi:10.3892/ijo.2019.4926

Mouw, K. W., Goldberg, M. S., Konstantinopoulos, P. A., \& D'Andrea, A. D. (2017). DNA Damage and Repair Biomarkers of Immunotherapy Response. Cancer Discov, 7(7), 675693. doi:10.1158/2159-8290.Cd-17-0226

Nicolini, Andrea, Ferrari, Paola, \& Duffy, Michael J. (2018). Prognostic and predictive biomarkers in breast cancer: Past, present and future. Seminars in cancer biology, 52(Pt 1), 56-73. doi:10.1016/j.semcancer.2017.08.010

Qiao, K., Ning, S., Wan, L., Wu, H., Wang, Q., Zhang, X., Xu, S., \& Pang, D. (2019). LINC00673 is activated by YY1 and promotes the proliferation of breast cancer cells via the miR-5155p/MARK4/Hippo signaling pathway. J. Exp. Clin. Cancer Res., 38(1), 418. doi:10.1186/s13046-019-1421-7

Qiu, Zhu, Li, Yunhai, Zeng, Beilei, Guan, Xiaoqin, \& Li, Hongzhong. (2018). Downregulated $\mathrm{CDKN} 1 \mathrm{C} / \mathrm{p} 57$ drives tumorigenesis and associates with poor overall survival in breast cancer. Biochemical and biophysical research communications, 497(1), 187-193. doi:10.1016/j.bbrc.2018.02.052

Rhodes, D. R., Yu, J., Shanker, K., Deshpande, N., Varambally, R., Ghosh, D., Barrette, T., Pandey, A., \& Chinnaiyan, A. M. ONCOMINE: a cancer microarray database and integrated data-mining platform. Neoplasia, 6(1), 1-6. doi:10.1016/s1476-5586(04)800472

Richardson, A. L., Wang, Z. C., De Nicolo, A., Lu, X., Brown, M., Miron, A., Liao, X., Iglehart, J. D., Livingston, D. M., \& Ganesan, S. (2006). X chromosomal abnormalities in basallike human breast cancer. Cancer Cell, 9(2), 121-132. doi:10.1016/j.ccr.2006.01.013 
408

409

410

411

412

413

414

415

416

417

418

419

420

421

422

423

424

425

426

427

428

429

430

431

432

433

434

Roche, E. F., McGowan, A., Koulouri, O., Turgeon, M. O., Nicholas, A. K., Heffernan, E., ElKhairi, R., Abid, N., Lyons, G., Halsall, D., Bonomi, M., Persani, L., Dattani, M. T., Gurnell, M., Bernard, D. J., \& Schoenmakers, N. (2018). A novel IGSF1 mutation in a large Irish kindred highlights the need for familial screening in the IGSF1 deficiency syndrome. Clin. Endocrinol. (Oxf), 89(6), 813-823. doi:10.1111/cen.13827

Sun, Y., Bak, B., Schoenmakers, N., van Trotsenburg, A. S., Oostdijk, W., Voshol, P., Cambridge, E., White, J. K., le Tissier, P., Gharavy, S. N., Martinez-Barbera, J. P., Stokvis-Brantsma, W. H., Vulsma, T., Kempers, M. J., Persani, L., Campi, I., Bonomi, M., Beck-Peccoz, P., Zhu, H., Davis, T. M., Hokken-Koelega, A. C., Del Blanco, D. G., Rangasami, J. J., Ruivenkamp, C. A., Laros, J. F., Kriek, M., Kant, S. G., Bosch, C. A., Biermasz, N. R., Appelman-Dijkstra, N. M., Corssmit, E. P., Hovens, G. C., Pereira, A. M., den Dunnen, J. T., Wade, M. G., Breuning, M. H., Hennekam, R. C., Chatterjee, K., Dattani, M. T., Wit, J. M., \& Bernard, D. J. (2012). Loss-of-function mutations in IGSF1 cause an X-linked syndrome of central hypothyroidism and testicular enlargement. Nat. Genet., 44(12), $1375-$ 1381. doi:10.1038/ng.2453

Tang, Xiaolong, Shi, Lei, Xie, Ni, Liu, Zuojun, Qian, Minxian, Meng, Fanbiao, Xu, Qingyang, Zhou, Mingyan, Cao, Xinyue, Zhu, Wei-Guo, \& Liu, Baohua. (2017). SIRT7 antagonizes TGF- $\beta$ signaling and inhibits breast cancer metastasis. Nature communications, 8(1), 318 . doi:10.1038/s41467-017-00396-9

Thutkawkorapin, J., Picelli, S., Kontham, V., Liu, T., Nilsson, D., \& Lindblom, A. (2016). Exome sequencing in one family with gastric- and rectal cancer. BMC Genet., 17, 41. doi:10.1186/s12863-016-0351-z

Wang, H. X., Sharma, C., Knoblich, K., Granter, S. R., \& Hemler, M. E. (2015). EWI-2 negatively regulates TGF- $\beta$ signaling leading to altered melanoma growth and metastasis. Cell Res., 25(3), 370-385. doi:10.1038/cr.2015.17

Woolston, C. (2015). Breast cancer. Nature, 527(7578), S101. doi:10.1038/527S101a

Yang, J., Song, H., Chen, L., Cao, K., Zhang, Y., Li, Y., \& Hao, X. (2019). Integrated analysis of 
435

436

437

438

439

440

441

442

443

444

445

446

447

448

449

450

451

452

453

454

455

456

457

458

459

460

461

microfibrillar-associated proteins reveals MFAP4 as a novel biomarker in human cancers. Epigenomics, 11(1), 1635-1651. doi:10.2217/epi-2018-0080

Yu, Yue, Luo, Wei, Yang, Zheng-Jun, Chi, Jiang-Rui, Li, Yun-Rui, Ding, Yu, Ge, Jie, Wang, Xin, \& Cao, Xu-Chen. (2018). miR-190 suppresses breast cancer metastasis by regulation of TGF- $\beta$-induced epithelial-mesenchymal transition. Molecular cancer, 17(1), 70. doi:10.1186/s12943-018-0818-9

Zhao, H., Langerød, A., Ji, Y., Nowels, K. W., Nesland, J. M., Tibshirani, R., Bukholm, I. K., Kåresen, R., Botstein, D., Børresen-Dale, A. L., \& Jeffrey, S. S. (2004). Different gene expression patterns in invasive lobular and ductal carcinomas of the breast. Mol. Biol. Cell, 15(6), 2523-2536. doi:10.1091/mbc.e03-11-0786

Zhao, Yuanyuan, Ma, Jing, Fan, Yanling, Wang, Zhiyong, Tian, Ran, Ji, Wei, Zhang, Fei, \& Niu, Ruifang. (2018). TGF- $\beta$ transactivates EGFR and facilitates breast cancer migration and invasion through canonical Smad3 and ERK/Sp1 signaling pathways. Molecular oncology, 12(3), 305-321. doi:10.1002/1878-0261.12162Zhang, Q., Lu, S., Li, T., Yu, L., Zhang, Y., Zeng, H., Qian, X., Bi, J., \& Lin, Y. (2019). ACE2 inhibits breast cancer angiogenesis via suppressing the VEGFa/VEGFR2/ERK pathway. J Exp Clin Cancer Res, 38(1), 173. doi:10.1186/s13046-019-1156-5

\section{Figure legends}

Figure 1: (A) Bioinformatics analysis of IGSF10 expression in TCGA database. (B) The expression of the IGSF10 mRNA in BC tissues and matched adjacent normal tissues was evaluated using qRT-PCR $(\mathrm{n}=21)$. (C-F) Representative images of IHC staining in BC specimens and adjacent normal breast tissues. (G) IHC score for the level of the IGSF10 protein expression in $31 \mathrm{BC}$ tissues (IHC score: $3.12 \pm 2.04$ ) and 31 normal tissues (IHC score: $4.45 \pm 2.13$ ). Data are presented as mean $\pm \mathrm{SD}$, unpaired t-test, $* P<0.05$. (H) qRTPCR was used to examine IGSF10 expression in human breast cancer cells and MCF-10A cells; $* P<0.05, * * P<0.01$, and ${ }^{* * *} P<0.001$. 
462

463 Figure 2: Kaplan-Meier survival curve of TCGA patients with breast cancer stratified into the IGSF10-high and IGSF10-low groups based on the median expression level. $P<0.05$ was considered a statistically significant. (A) Curves showing the OS of patients with breast

467 cancer. (B) Curves showing the RFS of patients with breast cancer.

Figure 3: (A) IGSF10 expression in patients with different molecular subtypes of breast cancer in TCGA database. (B) Basal breast cancer, (C) luminal A breast cancer, (D) luminal B breast cancer, and (E) HER2+ breast cancer. All the curves showing OS were plotted using the Kaplan-Meier plotter (http://kmplot.com/analysis/). $* * P<0.01$.

472

Figure 4: Gene sets with a normal $P$-value $<0.05$ and an $\mathrm{FDR}<0.25$ were considered significant. Gene sets were ranked by the normalized enrichment score (NES). (A) Gene sets enriched in the GSE1456 dataset. (B) Gene sets enriched in the TCGA dataset. (C-E) GSEA enrichment plot 476 showing that IGSF10 expression was positively associated with DNA repair, cell cycle, and 477 glycolysis. (F-G) GSEA enrichment plot showing that IGSF10 expression was positively 478 correlated with the PI3K/Akt/mTOR and mTORC1 signaling pathways. 


\section{Figure 1}

expression of IGSF10 in breast cancer

(A) Bioinformatics analysis of IGSF10 expression in TCGA database. (B)The expression of the IGSF10 mRNA in BC tissues and matched adjacent normal tissues was evaluated using qRTPCR $(n=21)$. (C-F) Representative images of IHC staining in BC specimens and adjacent normal breast tissues. (G) IHC score for the level of the IGSF10 protein expression in 31 BC tissues (IHC score: $3.12 \pm 2.04$ ) and 31 normal tissues (IHC score: $4.45 \pm 2.13$ ). Data are presented as mean $\pm S D$, unpaired t-test, ${ }^{*} P<0.05$. (H) qRT-PCR was used to examine IGSF10 expression in human breast cancer cells and MCF-10A cells; $* P<0.05, * * P<0.01$, and $* * * P<0.001$. 
A

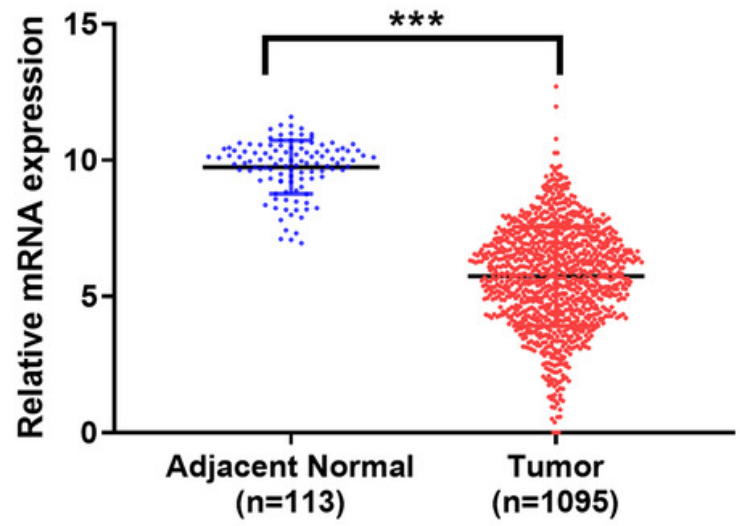

B

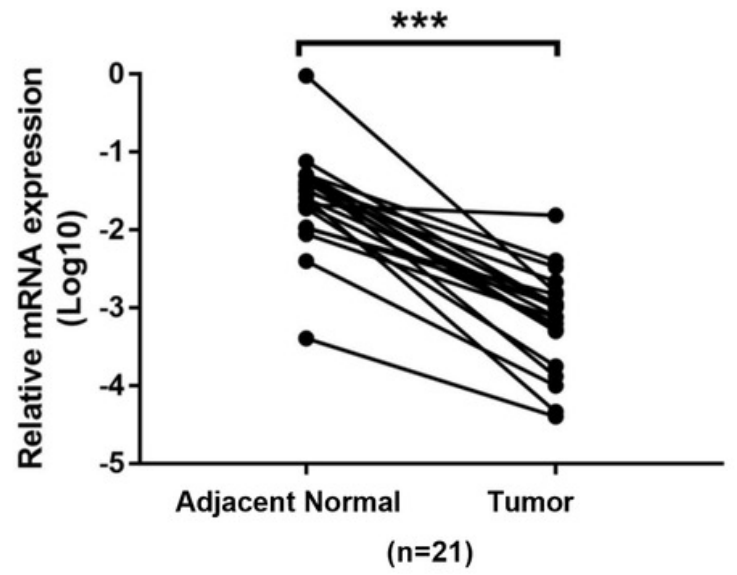

C

D

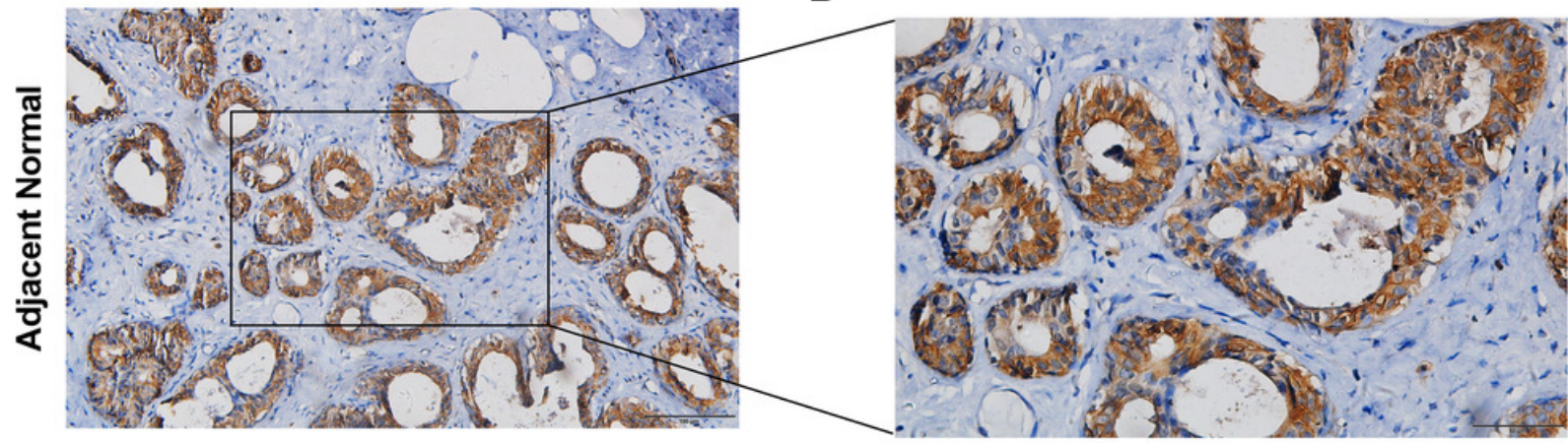

$\mathbf{E}$

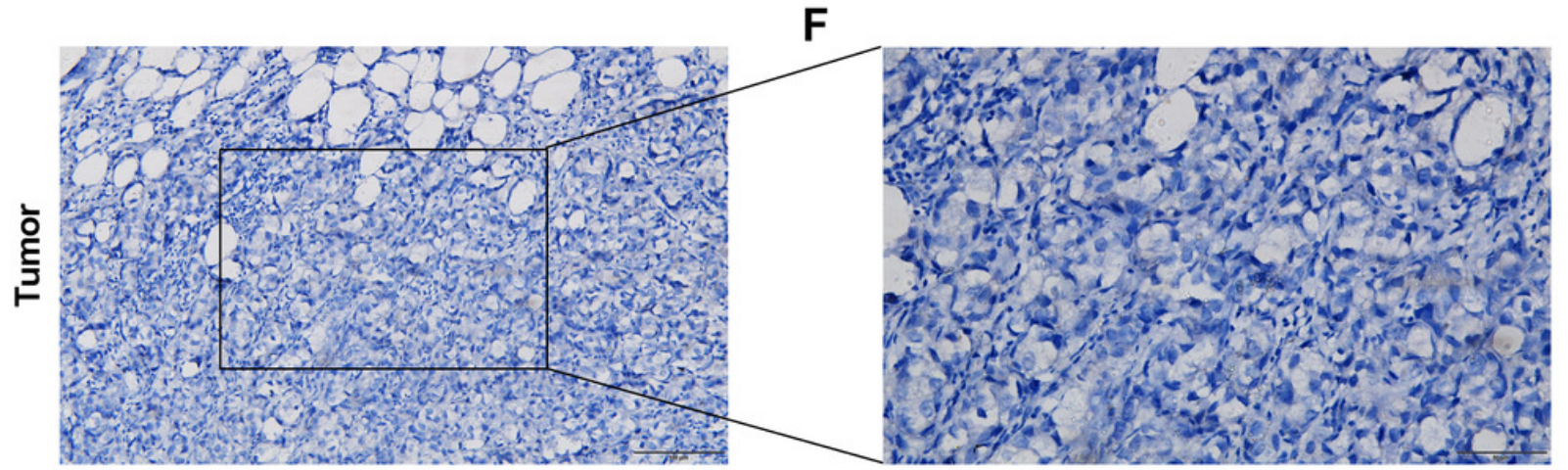

G

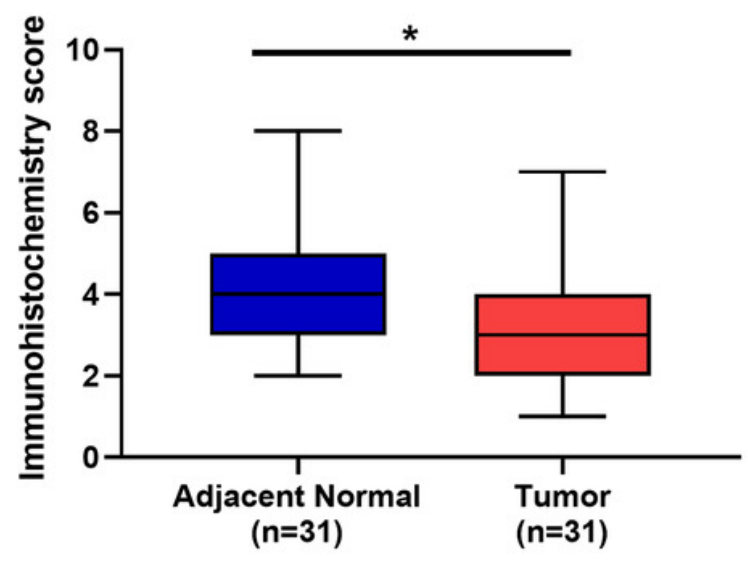

H

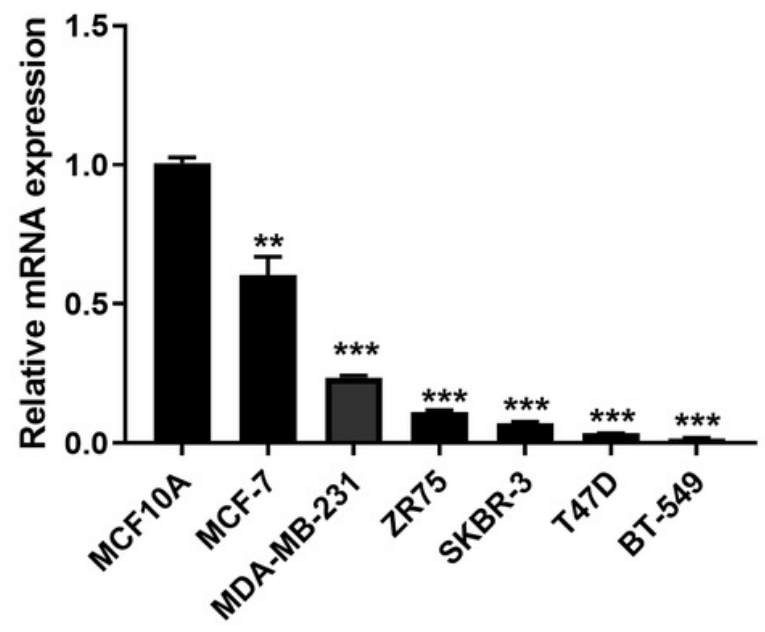


Figure 2

Kaplan-Meier survival curve was plotted with TCGA cohort by stratifying patients into IGSF10 high and low groups with median expression value.

Kaplan-Meier survival curve of TCGA patients with breast cancer stratified intothe IGSF10high and IGSF10-low groups based on the median expression level. $P<0.05$ was considered a statistically significant. (A) Curves showing the OS of patients with breast cancer. (B) Curves showing the RFS of patients with breast cancer.

A

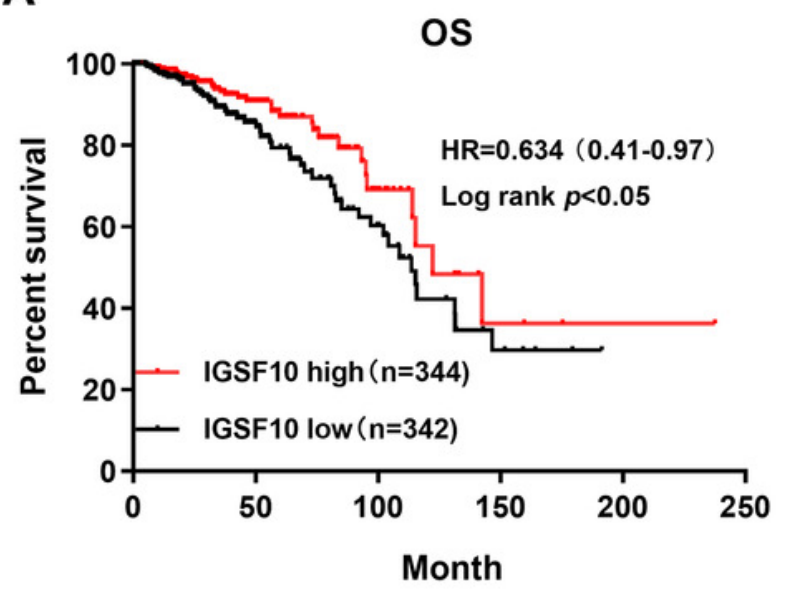

B

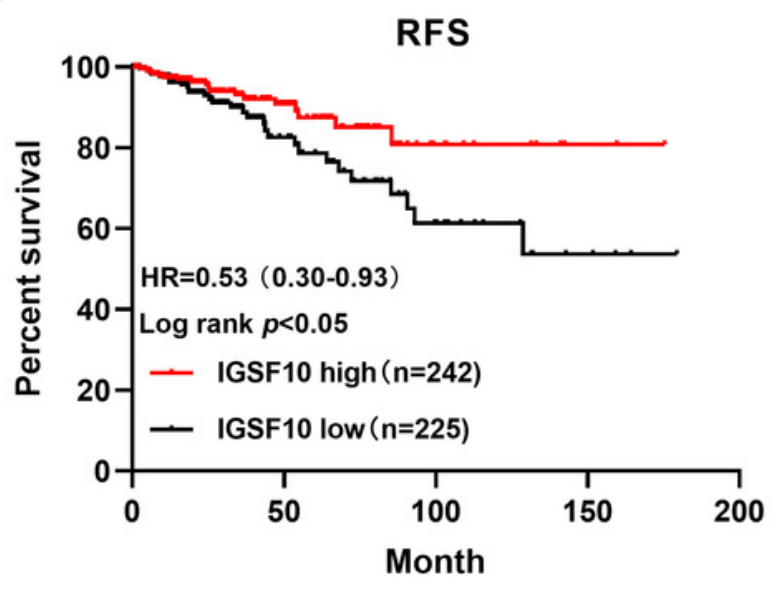




\section{Figure 3}

Overall survival of different molecular subtypes of breast cancer

(A) IGSF10 expression in patients with different molecular subtypes of breast cancer in TCGA database. (B) Basal breast cancer, (C) luminal A breast cancer, (D) luminal B breast cancer, and (E) HER2+ breast cancer. All the curves showing OS were plotted using the Kaplan-Meier plotter (http://kmplot.com/analysis/). ${ }^{* * P}<0.01$. 
A Expression of IGSF10

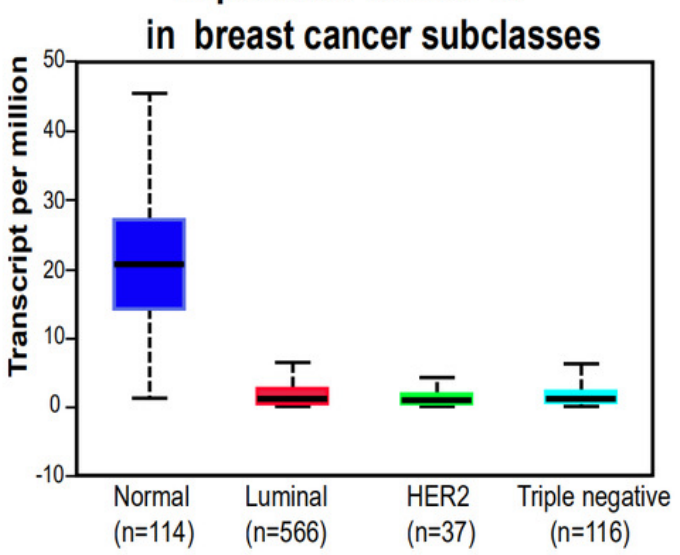

TCGA samples

C

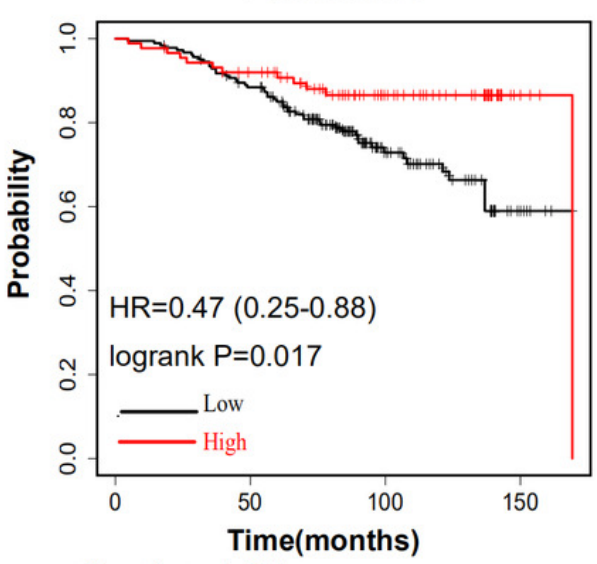

Number at risk

Low $\quad \begin{array}{lllll}183 & 158 & 59 & 7\end{array}$

High $\quad \begin{array}{lllll}88 & 77 & 38 & 6\end{array}$

E

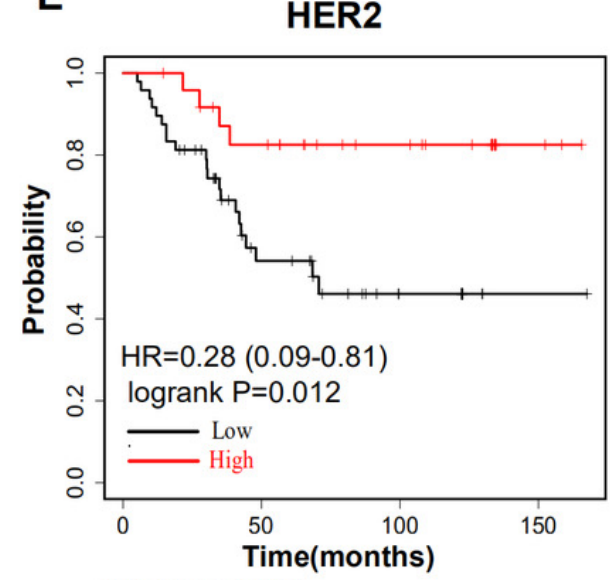

Number at risk

$\begin{array}{lllll}\text { High } & 25 & 18 & 10 & 3\end{array}$

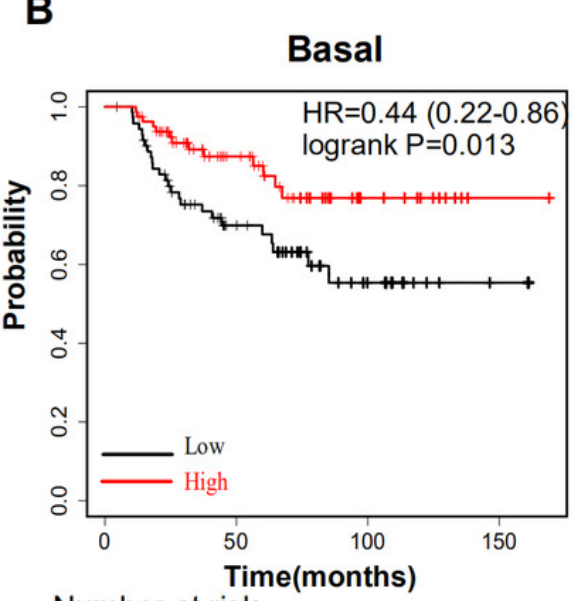

Number at risk

$\begin{array}{lllll}\text { Low } & 72 & 33 & 8 & 1\end{array}$

$\begin{array}{lllll}\text { High } & 81 & 41 & 11 & 1\end{array}$

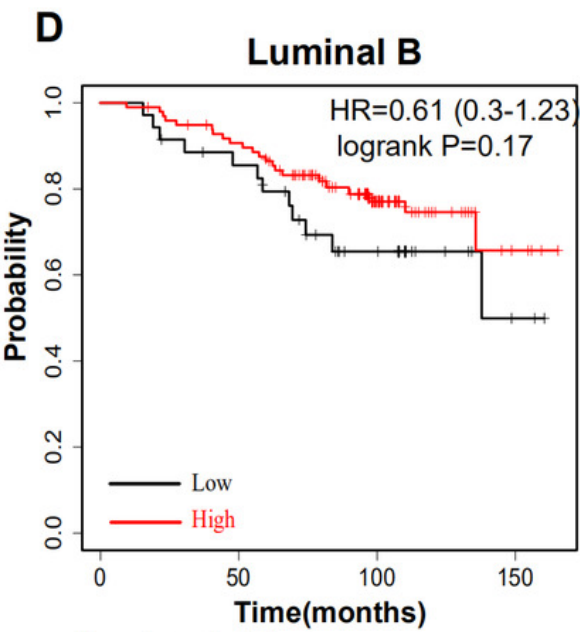

Number at risk

$\begin{array}{lllll}\text { Low } & 34 & 27 & 12 & 2 \\ \text { High } & 95 & 83 & 39 & 4\end{array}$




\section{Figure 4}

The gene sets that were significantly associated with IGSF10 with normal $P$-value $<0.05$ and false discovery rate (FDR) $<0.25$.

Gene sets with a normal $P$-value $<0.05$ and an FDR $<0.25$ were considered significant. Gene sets were ranked by the normalized enrichment score (NES). (A) Gene sets enriched in the GSE1456 dataset. (B) Gene sets enriched in the TCGA dataset. (C-E) GSEA enrichment plot showing that IGSF10 expression was positively associated with DNA repair, cell cycle, and glycolysis. (F-G) GSEA enrichment plot showing that IGSF10 expression was positively correlated with the PI3K/Akt/mTOR and mTORC1 signaling pathways. 
A

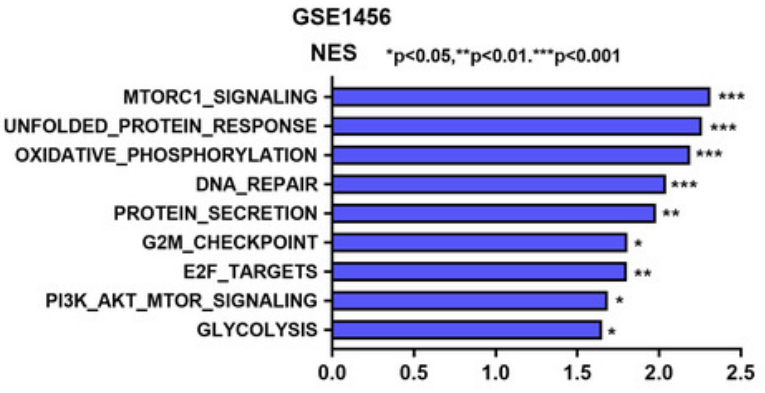

C

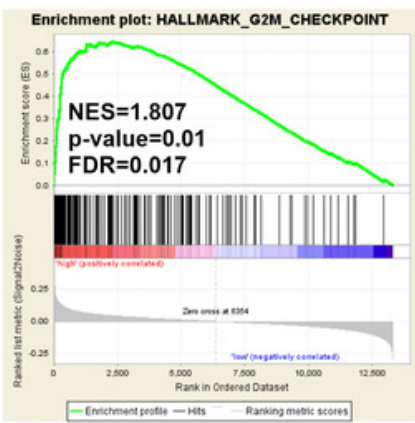

$\mathbf{F}$

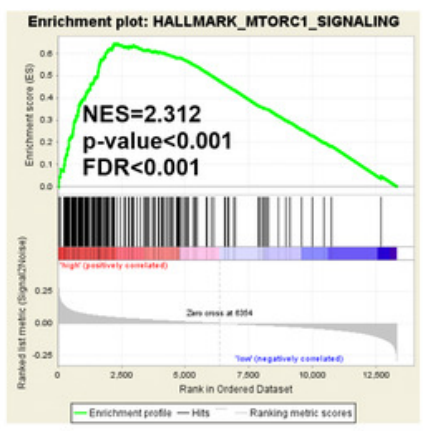

G
B

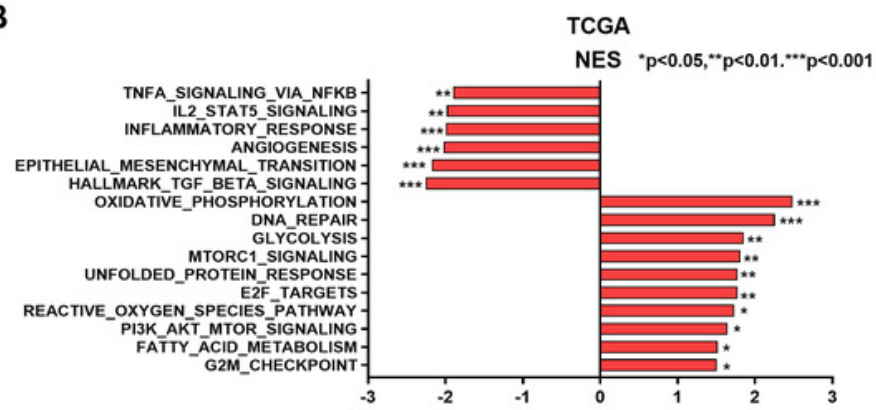

D

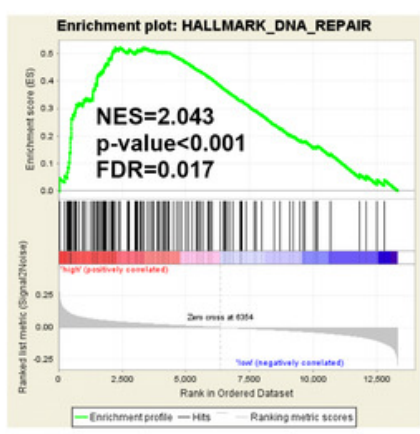

E

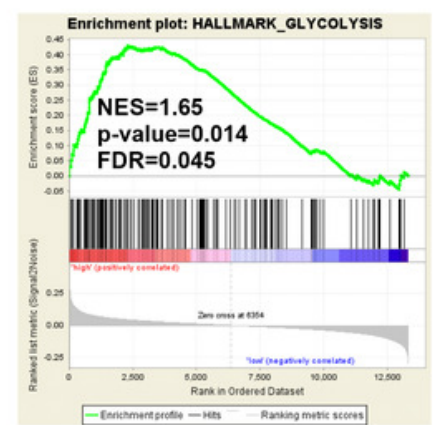

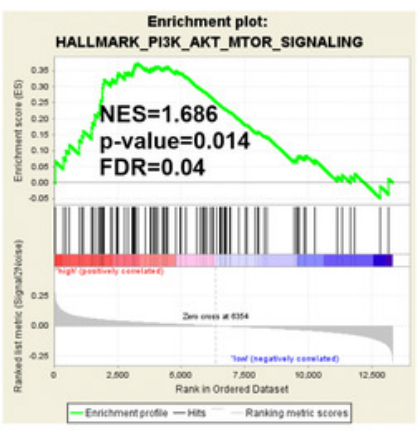




\section{Table $\mathbf{1}$ (on next page)}

clinical correlation of IGSF10 in breast cancer

Seven hundred patients with breast cancer in the TCGA cohort were analyzed to further confirm the correlation between IGSF10 expression and breast cancer 
Table 1. Clinicopathological features of TCGA breast cancer patients

\begin{tabular}{|c|c|c|c|c|}
\hline \multirow{2}{*}{ Characteristic } & \multirow{2}{*}{ Number of Cases } & \multicolumn{3}{|c|}{ IGSF10 } \\
\hline & & $\operatorname{High}(n)$ & Low $(n)$ & $P$-value \\
\hline \multicolumn{5}{|l|}{ Age } \\
\hline$<50$ & 193 & 125 & 68 & $<0.001^{*}$ \\
\hline$\geq 50$ & 507 & 242 & 265 & \\
\hline \multicolumn{5}{|l|}{ Tumor Size } \\
\hline $\mathrm{T} 1$ & 183 & 114 & 69 & $0.003 *$ \\
\hline $\mathrm{T} 2$ & 418 & 207 & 211 & \\
\hline $\mathrm{T} 3$ & 75 & 39 & 36 & \\
\hline $\mathrm{T} 4$ & 24 & 7 & 17 & \\
\hline \multicolumn{5}{|l|}{ Lymph node metastasis } \\
\hline No & 342 & 181 & 161 & 0.865 \\
\hline N1 & 236 & 119 & 117 & \\
\hline $\mathrm{N} 2$ & 85 & 47 & 38 & \\
\hline N3 & 37 & 20 & 17 & \\
\hline \multicolumn{5}{|l|}{ TMN Stage } \\
\hline I & 124 & 78 & 46 & $0.03 *$ \\
\hline II & 407 & 203 & 204 & \\
\hline III & 156 & 82 & 74 & \\
\hline IV & 13 & 4 & 9 & \\
\hline \multicolumn{5}{|l|}{ ER } \\
\hline Positive & 539 & 284 & 255 & 0.800 \\
\hline Negative & 161 & 83 & 78 & \\
\hline \multicolumn{5}{|l|}{ PR } \\
\hline Positive & 473 & 249 & 224 & 0.870 \\
\hline Negative & 227 & 118 & 109 & \\
\hline \multicolumn{5}{|l|}{ HER-2 } \\
\hline Positive & 102 & 53 & 49 & 0.918 \\
\hline Negative & 598 & 314 & 284 & \\
\hline \multicolumn{5}{|c|}{ Triple Negative Breast Cancer } \\
\hline Yes & 119 & 61 & 58 & 0.779 \\
\hline No & 581 & 306 & 275 & \\
\hline
\end{tabular}

Abbreviation: ER: estrogen receptor, PR: progesterone receptor. $\mathrm{p}<0.05$ was considered statistically significant. 
Table 2 (on next page)

Univariate and multivariate Cox regression analysis of IGSF10 in TCGA cohort. 
Table 2. Univariate and multivariate Cox regression analysis of IGSF10 in TCGA cohort.

\begin{tabular}{|c|c|c|c|c|c|c|c|c|c|c|c|c|}
\hline \multirow[t]{3}{*}{ Variants } & \multicolumn{6}{|l|}{ OS } & \multicolumn{6}{|l|}{ RFS } \\
\hline & \multicolumn{3}{|c|}{ Univariate analysis } & \multicolumn{3}{|c|}{ Multivariate analysis } & \multicolumn{3}{|c|}{ Univariate analysis } & \multicolumn{3}{|c|}{ Multivariate analysis } \\
\hline & HR & $95 \% \mathrm{CI}$ & $\begin{array}{l}p- \\
\text { value }\end{array}$ & HR & $95 \% \mathrm{CI}$ & $\begin{array}{l}p \text { - } \\
\text { value }\end{array}$ & HR & $95 \% \mathrm{CI}$ & $\begin{array}{l}p \text { - } \\
\text { value }\end{array}$ & HR & $95 \% \mathrm{CI}$ & $\begin{array}{l}p- \\
\text { value }\end{array}$ \\
\hline Age $(<50$ vs. $\geq 50)$ & $\begin{array}{r}0.59 \\
7\end{array}$ & $\begin{array}{l}0.358- \\
0.997\end{array}$ & $0.049 *$ & $\begin{array}{r}0.62 \\
6\end{array}$ & $\begin{array}{l}0.367- \\
1.069\end{array}$ & 0.086 & $\begin{array}{r}0.76 \\
8\end{array}$ & $\begin{array}{l}0.433- \\
0.945\end{array}$ & $0.041^{*}$ & $\begin{array}{c}0.66 \\
9\end{array}$ & $\begin{array}{l}0.373- \\
1.245\end{array}$ & 0.178 \\
\hline Tumor size (T1/T2 vs. T3/T4) & $\begin{array}{r}0.82 \\
5\end{array}$ & $\begin{array}{l}0.493- \\
1.380\end{array}$ & 0.464 & & & & $\begin{array}{r}0.61 \\
4\end{array}$ & $\begin{array}{l}0.322- \\
1.170\end{array}$ & 0.138 & & & \\
\hline $\begin{array}{l}\text { Lymph node (N0 vs. } \\
\text { N1/N2/N3) }\end{array}$ & $\begin{array}{r}0.60 \\
3\end{array}$ & $\begin{array}{l}0.384- \\
0.947\end{array}$ & $0.028 *$ & $\begin{array}{r}0.95 \\
4\end{array}$ & $\begin{array}{l}0.534- \\
1.704\end{array}$ & 0.873 & $\begin{array}{r}0.75 \\
3\end{array}$ & $\begin{array}{l}0.443- \\
1.279\end{array}$ & 0.294 & & & \\
\hline TNM stage (I/II vs. III/IV) & $\begin{array}{r}0.48 \\
2\end{array}$ & $\begin{array}{l}0.311- \\
0.747\end{array}$ & $0.001 *$ & $\begin{array}{r}0.53 \\
8\end{array}$ & $\begin{array}{l}0.307- \\
0.944\end{array}$ & $0.031^{*}$ & $\begin{array}{r}0.46 \\
7\end{array}$ & $\begin{array}{l}0.359- \\
0.785\end{array}$ & $0.001 *$ & $\begin{array}{c}0.59 \\
7\end{array}$ & $\begin{array}{l}0.347- \\
0.842\end{array}$ & $0.012^{*}$ \\
\hline ER (negative vs. positive) & $\begin{array}{r}1.19 \\
7\end{array}$ & $\begin{array}{l}0.734- \\
1.951\end{array}$ & 0.471 & & & & $\begin{array}{r}1.05 \\
6\end{array}$ & $\begin{array}{l}0.584- \\
1.909\end{array}$ & 0.858 & & & \\
\hline PR (negative vs. positive) & $\begin{array}{r}1.48 \\
9\end{array}$ & $\begin{array}{l}0.960- \\
2.311\end{array}$ & 0.076 & & & & $\begin{array}{r}0.95 \\
8\end{array}$ & $\begin{array}{l}0.547- \\
1.680\end{array}$ & 0.882 & & & \\
\hline HER2 (negative vs. positive) & $\begin{array}{r}1.09 \\
3\end{array}$ & $\begin{array}{l}0.563- \\
2.122\end{array}$ & 0.793 & & & & $\begin{array}{r}1.38 \\
8\end{array}$ & $\begin{array}{l}0.626- \\
3.077\end{array}$ & 0.419 & & & \\
\hline IGSF10 (low vs. high) & $\begin{array}{r}1.64 \\
5\end{array}$ & $\begin{array}{l}1.054- \\
2.569\end{array}$ & $0.029 *$ & $\begin{array}{r}1.79 \\
3\end{array}$ & $\begin{array}{l}1.141- \\
2.815\end{array}$ & $0.011 *$ & $\begin{array}{r}2.10 \\
2\end{array}$ & $\begin{array}{l}1.222- \\
3.615\end{array}$ & $0.006^{*}$ & $\begin{array}{c}2.29 \\
8\end{array}$ & $\begin{array}{l}1.317- \\
4.010\end{array}$ & $0.003^{*}$ \\
\hline
\end{tabular}

Abbreviation: OS: overall survival; RFS: relapse-free survival; HR: hazard ratio; CI: confidence interval; $p<0.05$ was considered statistically significant 